\title{
Understanding spatial concepts at the geographic scale without the use of vision
}

\author{
Robert M. Kitchin, Mark Blades \\ and Reginald G. Golledge
}

School of Geosciences, Queen's University of Belfast, Belfast BT7 1NN, UK Department of Psychology, University of Sheffield, Sheffield S10 2TN, UK

Department of Geography, University of California, Santa Barbara, California CA 93106, USA

\begin{abstract}
In this article we review the literature that has sought to determine the spatial understanding of people with visual impairments or blindness. In particular, we examine the arguments surrounding whether people with visual impairments or blindness can understand geographic relationships such as distance, configuration and hierarchy. At present, the conclusions of researchers can be divided into three camps. One group suggests that vision is the spatial sense par excellence. This group suggests that congenitally blind individuals (blind from birth) are incapable of spatial thought because they have never experienced the perceptual processes (e.g., vision) necessary to comprehend spatial arrangements. Another group suggests that people with visual impairments can understand and mentally manipulate spatial concepts, but because information is based upon auditory and haptic cues this knowledge and comprehension is inferior to that based upon vision. The third group suggests that visually impaired individuals possess the same abilities to process and understand spatial concepts and that any differences, either in quantitative or qualitative terms, can be explained by intervening variables such as access to information, experience or stress. To date, most of the research which has led to these conclusions has been conducted using small-scale, laboratory environments and, as yet, we are still unsure as to how people with visual impairments and blindness learn, store and process spatial information at the geographic scale. We suggest that more research is needed to understand more fully the 'mental landscapes' of people with blindness or visual impairments. Such research is necessary, particularly given the rapid growth of orientation and navigation aids in recent years aimed at increasing independent mobility. However, research must move out of the laboratory to examine spatial thought within the geographic environments that people with visual impairments or blindness interact with on a daily basis.
\end{abstract}

\section{Introduction}

Vision is often quoted as the spatial sense par excellence (Foulke, 1983). As a result, it is widely contended that people with severe visual impairment or blindness experience a 
world different from those who are sighted (see Spencer et al., 1989). This has led researchers such as Golledge (1993a) to argue that beyond communicating by reading and writing, the inability to travel independently and to interact with the wider world is the most significant problem produced by visual impairment or blindness. Indeed, ClarkCarter et al. (1986) reported that at least $30 \%$ of people with visual impairment or blindness make no independent journeys outside their homes and most of those venturing outside their home independently adhere to known routes, as exploration can lead to disorientation and chaos, accompanied by the fear, stress and panic associated with being lost (Golledge, 1993a; Hill et al., 1993). However, our spatial understanding of the world experienced by people with severe visual impairments remains relatively sparse. Our argument here is that cognitive mapping research allows an insight into the 'mental landscapes' of people with blindness or visual impairments and, as such, has the potential to shed light upon what spatial and environmental information they acquire, how it is learnt, and how it is processed and stored (Pick, 1980; Golledge et al., 1996a).

The reasons for trying to understand how people with severe visual impairment comprehend the world, and in particular its spatial aspects, are persuasive. For example, it is essential that people with visual impairments or blindness understand where they are in the geographic environment and how an action or activity alters their position with respect to known locations within that environment (Spencer et al., 1989). Like a sighted individual, a person who is vision impaired or blind must be able to traverse space at a reasonable pace (Golledge, 1993a) and undertake such mobility with grace, comfort and safety (Foulke, 1983). In addition, such a comprehension is important as it relates to issues such as quality of life through improving educational curricula, planning environments that are easy to learn and remember, and the development of technical aids for mobility and navigation. Indeed, with the accelerating development of new technological aids for blind people such as NOMAD (an audio-tactile graphics processor; Parkes, 1988), personal guidance systems (Golledge et al., 1991; Balachandran, 1995; Petrie, 1995), talking signs (Brabyn, 1995), and Atlas Speaks (a talking map; Fruchterman, 1995), the need for an effective and reliable assessment of the spatial knowledge structures of vision-impaired people becomes even more apparent.

At present, many potential employment opportunities are denied to blind or visionimpaired people because the job requires spatial actions which are (perceived to be) beyond the ability of a blind or severely impaired person (e.g., computer operator, safely driving a car in traffic) or because the disabled person experiences difficulties in travelling to the workplace leading to reduced independence and truncated activity spaces. Indeed, there is a persistent attitude among the population in general that disabled people, and people who are blind or severely vision impaired in particular, must have little spatial ability or competence because of their lack of acute vision. However, Golledge et al. (1996b) report that disabled people can be found in vocations as widely different as disc jockeys at radio stations, transit district or radio cab dispatchers, piano tuners, store clerks, computer operators, teachers, presidents of companies and in many other types of employment. As such, lack of vision may not be the limitation to employability that it is often assumed to be. Consequently, one aspect of what is needed are insights into the nature of spatial ability and information on people with severe visual impairments and an appreciation as to what degree any lack of knowledge is a function of lack of training and opportunities to develop their spatial abilities. If this is the case, and reduced spatial ability and information are directly related to opportunities to develop specific skills, then it may be possible to devise ways to increase the spatial competence of blind or 
vision-impaired people in order to improve their employability and their quality of life. This is not to deny that there needs to be a general shift towards universal planning and better provision for disabled people, accompanied by a shift in the general population's attitudes and beliefs, but that it may be possible to increase quality of life through specific training schemes that enhance mobility.

In this article, we discuss the contribution of cognitive mapping studies to such developments and suggest future directions for research. How knowledge of spatial relationships is structured and how new environments are learnt are reviewed. Note, we are not arguing that people with severe visual impairments are not 'normal', just that they may have differing conceptualizations and understanding of spatial relationships. Similarly, it should be noted that while we acknowledge the argument of others concerning the socially constructed barriers to independent living and access to the workforce, this article will specifically discuss the contribution of cognitive mapping studies to understanding the geographic world of people with severe visual impairments. Cognitive mapping, because it requires respondents to undertake a series of experimental tests, might be considered in the category of a geography 'of' or 'for' disabled people and essentially functionalist. However, that is not necessarily so. For example, Vujakovic and Matthews (1994) adopted a sociopolitical model and used an empirical framework that allowed respondents to be actively involved in the research process by using their cognitive maps to define areas of accessibility in Coventry city centre. In other words, cognitive mapping research, and hence behavioural research, is not necessarily functional in nature but can also be emancipatory, adopting a 'geography with disabled people' stance which acknowledges the social production of space and the social construction of relationships (e.g., Kitchin, 1996a). In this sense, cognitive mapping research might best be seen as complementary to, rather than in opposition to, other studies which focus upon the experiences of disabled people interacting with the environment (e.g., Butler and Bowlby, 1996) and both forms of study can contribute to improving disabled people's quality of life.

\section{Cognitive mapping research}

Kitchin (1994) argued that a fundamental human need is the need to know about the world around us. Such knowledge structures our spatial behaviour and our sense of place. Cognitive mapping research focuses on understanding how we make sense of our surroundings and how we use knowledge to make spatial decisions and choices (Kitchin, 1994). As such, cognitive mapping concerns the study of how we consciously, or more often subconsciously, acquire, learn, develop, think about and store data relating to our everyday geographic environment, and the actual knowledge we acquire (Downs and Stea, 1973). Over the past 30 years researchers from geography, psychology, planning, architecture and cognitive science have made significant advances in understanding spatial thought. Kitchin (1996b) reported that a number of theories have been advanced to account for how knowledge is learnt, stored and structured. For example, landmarkbased learning strategies have been proposed by Golledge (1978) and route-based strategies by Allen $(1981 ; 1982)$. The mechanism of information storage varies between images (Kosslyn and Pomerantz, 1977), propositions (Anderson and Bower, 1973), dual coding (Paivio, 1979) and genetic coding (Fishbein, 1976). Similarly, various theories exist concerning how this knowledge is structured, with network (Kaplan, 1973), hierarchical 
(McNamara, 1986) and partial hierarchical (Stevens and Coupe, 1978) configurations being forwarded. Theories have also been put forward to discuss the development of spatial thought across the lifespan (e.g., Piaget and Inhelder, 1967; Werner, 1957; Hart and Moore, 1973; Siegel and White, 1975) and researchers have discussed the constituent components (e.g., Golledge, 1993b) and knowledge structures (e.g., Liben, 1981) associated with spatial thought.

At present, we are unsure how these theories relate to blind or visually impaired people, particularly in large environments. To date, most research into blind people's spatial ability has concentrated upon the conceptualization of small-scale spaces such as a room (Tellevik, 1992; Haber et al., 1993; Hill et al., 1993) or a building (Passini and Proulx, 1988) and hypothetical spaces such as a purpose-built maze in a room (Klatzky et al., 1990; Passini et al., 1990) with little research into large-scale geographic spaces such as an urban park or a residential area (Byrne and Salter, 1983; Rieser et al., 1992). Other researchers have concentrated upon how visually impaired individuals learn an environment through different media, such as tactile maps (Golledge, 1991; Jacobson, 1992; Ungar et al., 1994). A few researchers have tested blind people's wayfinding performance in real environments, but most have only asked individuals to walk a short route with one or two choice points (e.g., Leonard and Newman, 1967; Dodds et al., 1982; Herman et al., 1983). As there has been little research concerning how blind and visually impaired people understand spatial relationships and concepts at the geographic scale, our discussion will focus on cognitive mapping theories developed with work relating to sighted respondents. Where relevant, we have incorporated the results from studies of blind and visually impaired people and discussed how theories of cognitive mapping might relate to these groups.

Psychologists since the 1920s have engaged in a debate concerning sight and spatial ability. Much of this argument concerned the premise that without sight, spatial knowledge and spatial ability would be both diminished and impoverished. Researchers such as Banerjee (1928), Lund (1930) and von Senden (1932) established the existence of significant veering trends in blind and blindfolded sighted populations, as well as finding that blind people performed less well than sighted participants on a number of shape recognition and wayfinding tasks. However, Worchel (1951) and Cratty (1966) provided evidence of significant spatial abilities in blind or vision-impaired populations using relatively large-scale real-world environments (e.g., areas the size of a footbal field). Further, Butler (1995) challenged the role of vision as the dominant sense in learning and comprehending spatial information. She suggested that a wealth of spatial information is available through other senses, such as haptics (touch in relation to the rest of the body) and echolocation. She argued that blind individuals can learn spatial concepts effectively, but it is the lack of experience of interacting with the environment which restricts their knowledge of places surrounding them. However, Butler provided no evidence to support the latter suggestion. These positions are reflected in three theories (Andrews, 1983) which seek to classify the results of the growing literature concerning the mobility, orientation and navigation of people with visual impairments or blindness.

Deficiency theory states that congenitally blind individals (blind from birth) are unable to develop a general spatial understanding because they have never experienced the perceptual processes (e.g., vision) necessary to comprehend two and three-dimensional arrangements, scale changes and more complex concepts such as hierarchy, pattern and continuity (see Golledge, 1993a). As a result, they lack the ability to perform complex mental spatial problem-solving involving rotations and transformations. The evidence for 
such a deficiency is derived from studies in which congenitally blind respondents have shown difficulty in understanding and applying spatial concepts (Dodds et al., 1982; Rieser et al., 1986). Adventitiously blind individuals (lost their sight later in life), however, because they have experienced the necessary perceptual processes do show evidence of spatial ability (Spencer et al., 1989). Inefficiency theory states that people with visual impairments can understand and mentally manipulate spatial concepts, but because information is based upon auditory and haptic cues this knowledge and comprehension are inferior to that based upon vision (see Spencer et al., 1989). Inefficiency theory states that people with visual impairments can understand and mentally manipulate spatial concepts, but because information is based upon auditory and haptic cues this knowledge and comprehension are inferior to that based upon vision (see Spencer et al., 1989). Difference theory states that visually impaired individuals possess the same abilities to process and understand spatial concepts, and that any differences, either in quantitative or qualitative terms, can be explained by intervening variables such as access to information, experience or stress (Passini and Proulx, 1988; Golledge, 1993a). All three theories suggest that congenitally blind individuals have trouble building a comprehensive cognitive map knowledge to the level of configurational knowledge, with deficiency theory stating that such knowledge is impossible. The position with adventiously blind and visually impaired individuals who have some residual vision is not so well known as they clearly either had or do possess access to visual perceptual cues necessary to develop spatial abilities. Most researchers now acknowledge that both congenitally and adventitiously blind individuals can process spatial data and complete tests designed to measure configurational knowledge, although their ability to complete these tasks is variable and sometimes poorer than sighted individuals. However, as pointed out, this conclusion has been mainly based on studies carried out in small-scale spaces or limited environments.

\section{Types of knowledge and knowledge structures}

Cognitive map knowledge consists of the items of information that form the constituent data, and the knowledge structures used in storing and processing this information. The constituent elements are both attributive (encoding information about a location) and locational (encoding where phenomena are sited) (Downs and Stea, 1973). For sighted individuals it is generally acknowledged that this knowledge develops through a series of three knowledge structures: declarative to procedural to configurational knowledge (Liben, 1991).

Liben (1981) described declarative knowledge as the mental database of specific spatial features. In this conceptualization declarative knowledge is regarded as landmark knowledge, although it can include linear features such as roads, or areal features, such as parks. Procedural knowledge consists of the rules used to synthesize the declarative knowledge database into information which can be used to facilitate an action. For the purpose of cognitive mapping these rules include wayfinding knowledge (which directs movement between places) and strategies for determining patterns, recognizing shapes, hierarchies, linkages, regions and other spatial relations. An example of the latter would be rules for transformation of path elements into a navigable route. This transformation however, is mechanistic and does not include the procedures for making inferences about routes never experienced. Research by Casey (1978) demonstrated that visually impaired people could combine experienced path elements as routes. He asked visually impaired 
students to make a model of their campus, and they were able to model familiar routes with some accuracy.

Thorndyke (1983) hypothesized that there are two different types of procedural knowledge. The first of these is unordered productions, where individual productions are independent in that they do not represent the order or occurrence of features along a route. Instead they represent how to get between individual places, so that an individual can retrieve the appropriate action at decision points, but cannot retrieve the order of decision points. Thorndyke (1983) cites the case of a colleague who stated that she could take him to a place but not direct him. Unordered productions also represent general rules of navigation applicable to routes never experienced before. The second type of procedural knowledge includes ordered productions. Here, order information represents associations between the productions and so whole routes can be remembered without having to travel along them. Hart and Berzok (1983) suggested that these ordered productions are also divided into three stages. Ordinal mapping is where individuals are almost certain of the sequence of places, but are less sure of the relative distances that separate the places. Interval mapping includes relative distances and times in the sequence but not direction. Hart and Berzok (1983) suggested that this is a common mapping strategy and give the example of commuting, where direction is not needed but places are tracked to give an idea of how much of a route has been accomplished. The third stage is accurate route map knowledge and contains these missing directional components providing an accurate set of procedural knowledge for a particular route. Butler et al. (1993) suggested that people prefer to use ordinal or interval procedural knowledge for wayfinding as they are easier to use. They found that newcomers to a complex building preferred using ordered signs rather than interpreting you-are-here maps where distance and direction had to be remembered. In parallel to some of this research, Haber et al. (1993) examined a variety of ways that vision-deficit people used to indicate location and direction, while Passini et al. (1990) have examined the way visiondeficit groups learn routes through complex environments (a maze) and take shortest paths back to the origin of the trip.

The highest level of cognitive map knowledge is called configurational knowledge and it surpasses procedural knowledge by incorporating information such as angles, directions, orientation, location and distance apart of places (Golledge et al., 1987) so the possessor has knowledge of the associations between, and the relative positions of, places; these form a comprehensive spatial knowledge system (Golledge, 1992). The ability to connect different and independent routes also exists and such knowledge has been termed 'commonsense knowledge' by Kuipers (1982) and allows inferences and propositions to be made (Allen, 1985). Thorndyke (1983) hypothesized that there are two types of configurational knowledge. First, schematized maps which contain simple, prototypical configurations of elements to form basic representations of an area. Hart and Berzok (1983) termed these 'loose topological mappings' and suggested that locations are mapped upon the basis of ordinal or categorical strategies, such as, 'near to', 'parallel to' and 'in front of'. Alternatively, detailed maps are well developed, hierarchically organized and are nearly veridical in nature, being built using co-ordinate strategies through extensive navigational experience. Secondly, Thorndyke (1983) suggested that route and configurational knowledge are linked by symbolic abstractions so that navigation based upon landmark and icon recognition is supplanted with semantic knowledge about the names of locations and routes. Klatzky and Lederman (1988) and Klatzky et al. (1990) have used tabletop location, triangle completion, and shape and layout recognition tasks 
to illustrate that vision-impaired or blind people have similar skills and abilities. Hollins and Kelly (1988) have also found clear evidence of configurational understanding by congenitally and adventitiously blind people. Other researchers have provided visually impaired people with environmental elements (e.g., model buildings, road pieces, Braille labels) and asked visually impaired people to construct representations of familiar environments. For example, Casey (1978) found that visually impaired students could produce models of a familiar campus, though their models were not as complete and well organized as models produced by sighted respondents. It may well be the case that visually impaired people have greater difficulty integrating familiar spaces and learning new spaces (e.g., Dodds et al., 1982; Hollyfield and Foulke, 1983; Reiser et al., 1986).

Golledge (1993b) hypothesized that the constituent elements of physical reality will have cognitive counterparts. His model details a comprehensive mental database which consists of seven components whose complexity and spatial structure differ. Golledge's (1993b) first component concerns the individual occurrences of phenomena. In physical reality phenomena such as buildings and landmarks exist as unique occurrences. These are characterized by identity, which is a name or label that can be attached to a phenomenon. This can be made place specific by attaching a unique location (e.g., Safeway in $X$ shopping centre) or class specific by attaching a generic label (e.g., supermarket). Each phenomenon also has a location. In physical reality these locations remain fixed, but in cognitive space frames of reference may become altered so that they are stored egocentrically, allocentrically, topologically or even multidimensionally, rather than within strict co-ordinate systems. The magnitude of a phenomenon will vary so that, just as phenomena in physical reality vary in size and volume and are categorized as such, phenomena within cognitive map knowledge will deviate. Each phenomenon also exists in time as well as space (Golledge, 1993b). It is believed that individual phenomena are of great importance in cognitive map knowledge. This is because individual phenomena with large subjective magnitudes form the anchors to which all the other information is attached and act as critical organizing nodes around which the cognitive map knowledge is developed (Golledge et al., 1985).

In reality, places are often connected together by routes or pathways and it is likely that such connections also exist in cognitive map knowledge (Couclelis et al., 1987). Spatial linkage and connectivity therefore form linear elements, which are thought to be the second basic building-block of cognitive map knowledge after individual phenomena. A higher level of organization in physical reality is a spatial distribution. This occurs when phenomena are grouped through common identity, magnitude, temporal or functional characteristics to expose a pattern or arrangement. Properties of spatial distributions include density, arrangement and the spatial variance of a set of phenomena (Golledge, 1993b). Such a process is also likely to occur in cognitive maps, where people may store in memory distributions of selected phenomena for specific uses (Couclelis et al., 1987).

Spatial contiguity relates to the spatial separation between phenomena. Distance between locations is important because it is the concept that links places in both cognitive and physical space (Golledge, 1993b). Places in physical reality and cognitive maps can be described as being proximal, clustered or separated. Places close to each other are likely to have some spatial association, that is some common link that makes them more alike. Distances in the cognitive map may differ from physical reality with symbolic, topological, projective spatial relations existing rather than Euclidean relations (Cadwallader, 1979; Tversky, 1981). 
When we classify a set of common phenomena, we at times stratify the data into classes in a hierarchical ordering. An example from physical reality would be that cities are larger than towns, which are larger than villages which are larger than hamlets (Golledge, 1993b). The reason for this stratification is to impose an order on reality to help understand the geographic world. Cognitive map knowledge reflects the same kind of categorization, but one based on both subjective judgements and physical facts (Stevens and Coupe, 1978; Hart and Berzok, 1983). Physical reality is a complex structure of phenomena involving many spatial components and it is likely that very few people actually possess a comprehensive cognitive spatial structure which contains all the information about locations, distributions, densities, dispersions, patterns, connections and hierarchies (Golledge, 1993b). Since much of the incentive for hierarchical classification is based on actual or perceived magnitudes or dominance, there is reason to suspect that this concept may be a more difficult one for blind or vision-impaired people to use in comprehending geographic layout. There is a paucity of research on this topic, and therefore little is known about visually impaired people's understanding and use of geographic hierarchies.

Frames of reference (or systems of reference) refer to the rotation and alignment heuristics used to aid remembrance of an environment (Tversky, 1981; Moar and Bower, 1983; Warren et al., 1990). They help us to orientate ourselves and give us a 'sense of direction' (Kuipers, 1978). These frames are often discussed in a developmental context, but they also apply to an adult learning a new environment (Tversky, 1992), but the utility of this concept to those with visual impairments or blindness is currently not well known.

An egocentric framework refers to knowledge which is tied to oneself. In a young child, a self-reference system operates so that a child knows where places exist through his or her own position (Hollins and Kelly, 1988). This can be divided into two substages. In the first stage children possess topological skills and know that places are within an area in relation to themselves. In the second stage, children become aware of proximity and concepts such as 'to-the-right-of', so that places are located within a system of asymmetrical co-ordinates, for example, left-right, near-far (Piaget and Inhelder, 1967; Pufall and Shaw, 1973). To establish more efficient geographic orientation however, children must progress to a system of reference which is independent of themselves (Hart and Berzok, 1983; Ungar et al., 1996).

A fixed framework is when knowledge is tied to features within the environment to produce a natural co-ordinate system. Fixed frames of reference exist because of the simple alignment and rotation heuristics or rules used to encode information and they are important because they allow individuals to use cognitive map knowledge to orientate themselves in a known area regardless of their position in the environment (Gärling et al., 1986). Tversky (1981) discussed three types of fixed frames of reference, in which cognitive map knowledge is aligned and rotated to features in the environment: axes of symmetry, mainline axes and landmark axes. These axes often result in distortions of alignment and rotation, because knowledge is rotated or translated to fit these natural coordinate systems (Lloyd, 1989). For example, axes of symmetry refer to natural features that bisect areas into two. Linear features may well be aligned so they run parallel to these features, thus distorting cognitive map knowledge if other features are tied to these linear features (Tversky, 1981). The same effect will happen when knowledge is organized with reference to mainline axis, such as, roads, railways and rivers.

Global frames of reference go beyond fixed frames and allow individuals to orientate themselves in unknown environments, regardless of the direction faced (Gärling et al., 
1986). With a global frame of reference it is possible to locate all other known places within the same frame of reference and examples of such systems include cardinal directions, mapping co-ordinates and latitude/longitude values. We are unaware of any work concerning such distortions with blind or visually impaired adult individuals.

At present, we are unsure as to whether people with visual impairments differ from sighted individuals in what they know about geographic space or in how their knowledge is structured. For example, does the lack of vision hinder the understanding of complex spatial concepts such as continuity, hierarchy and structure? Do the visually impaired use the same coding heuristics (alignment and rotation) to structure their knowledge? Do people with visual impairments or blindness understand and develop global frames of reference? Klatzky et al. (1990) suggest that blindfold sighted individuals build configurational knowledge of an area in an image form. Whether unsighted individuals would be able to construct such knowledge is relatively unknown. However, Rieser et al. (1986) found that blind and blindfolded sighted respondents were able to compute the directions of short cuts to known locations, although the sighted individuals outperformed the unsighted individuals. These short cuts, however, can be explained by an alternative homing vector strategy whereby an individual continually updates his or her current location to the origin location within a co-ordinate space without remembering the traversed path or environmental cues (Klatzky et al., 1990). Spencer et al. (1989) reported that it is widely believed that blind people, because of their lack of vision and their reliance on direct contact and self-referenced perception of places, encode information in a serial, egocentric manner. People who are congenitally blind, who have never had a simultaneous and direct perception of spatial relations and perspective, are limited to an egocentric route-type representation of space. The adventitiously blind, however, because they have had visual experience, may process and structure knowledge in ways similar to sighted individuals (Spencer et al., 1989).

Dodds et al. (1982), Byrne and Salter (1983) and Herman et al. (1983) found that blind individuals were poorer than blindfolded sighted individuals at pointing between indirectly connected places along a route. Fletcher $(1980 ; 1981)$ found that sighted individuals outperformed blind people on route and map-based tasks, and that blind people did better at the route than the map task. Studies investigating the estimation of distances also suggest that blind people rely on route information. For example, Rieser et al. (1980) found that blind people had more difficulty estimating Euclidean distances between locations than estimating functional distance (travelled distance) and Byrne and Salter (1983) found that although blind people had more difficulty estimating directions than distances, the latter estimates did not differ from sighted individual's estimates. In addition, blind people were much worse than the sighted when estimating directions from an imagined distant location rather than from their home. Bigelow (1991), in a similar pointing experiment, concluded that congenitally blind individuals based their knowledge of their home and close locations on known routes rather than on an Euclidean understanding of space.

Contrary to these findings Passini and Proulx (1988) found that congenitally blind individuals could learn a complex route through a building involving several turns and changes in elevation and were able to map the route and propose short cuts. In an earlier study, Passini et al. (1986) examined the wayfinding ability and activity patterns of blind and vision-impaired people in significantly large geographic spaces. First they compiled profiles of the members of groups of congenitally and adventitiously blinded individuals plus other groups with weak and strong residual sight. Passini et al. (1986) asked 
participants about the technical and human aids they regularly used in their wayfinding activities; the information they most valued during actual wayfinding behaviour; their history of mobility and orientation training; their evaluation of the difficulty associated with different physical obstacles and dangers likely to be encountered when traversing real-world environments; and their cognitive mapping abilities. With respect to the latter, Passini et al. (1986) examined participants' abilities to represent the structure and feature content of large-scale environments, and their evaluation of situations that produced spatial disorientation. And, finally, they assessed which environmental features contributed most to successful wayfinding and in which type of environments wayfinding was considered most difficult. Passini et al. (1986) found that all groups were able to develop proficiency in wayfinding in the large-scale environment where proficiency was defined as an ability to move unaided throughout an obstacle-ridden space. They also found that shopping complexes, department stores, hotel lobbies, train and bus stations, airport terminals, car parks, open spaces and parkland areas were the most difficult for vision-impaired or blind people to traverse. Other places that were crowded, exotic or which lacked distinctive auditory reference points to assist with orientation and location skills were also considered difficult environments. Indoors, the participants indicated that important information identifying reference points was often masked by soundabsorbing materials such as carpets or acoustic tiles, or by a high level of background noise (e.g., verbal discussion or loud music). In addition, participants in Passini et al.'s (1986) studies indicated that they had difficulty travelling through environments which did not lend themselves to ease of recognition and memorization. This happened when specific patterns were repeated multiple times over short distances (e.g., repetitively landscaped blocks, segments of stores arranged exactly the same way). On the other hand, some repetitive features were considered useful; examples included regularly gridded street layouts and uniform sizes of blocks of residential or other urban land uses.

Passini and Proulx (1988: 247) concluded that blind individuals do understand the 'geometric characteristics of a setting to an extent that is comparable to a sighted individual' and that any differences are due to distant cues and visual reference points not accessible to the individual. Passini et al. (1990) replicated these findings using a complex maze setting involving eight different tasks including inverting a route, combining routes, learning models and executing behaviour, making short cuts and mental rotations, and building models of a layout. Whether these representations are route or configurationally based is unknown. Juurmaa and Lehtinen-Railo (1994), who had respondents estimate the locations of objects within an array, also concluded that vision is not necessary for the generation of spatial patterns. They suggested that blind individuals are capable of spatial holistic images and thus have access to representations of configurations. They argued that differences occur between sighted and unsighted individuals because of the latter's 'lack of experience in bringing their representations into effective use and operation' (Juurmaa and Lehtinen-Railo, 1994: 170).

\section{Learning the geographic environment}

We can be certain that processes of learning and acquiring cognitive map knowledge involve the acquisition and filtering from the natural, built, social and cultural environments to which a person is exposed (Gale et al., 1990). In sighted individuals, knowledge of the geographic environment is thought to be almost solely based upon visual experience (Foulke, 1983). There are two main theories concerning how sighted individuals 
learn and develop cognitive map knowledge. One theory is that a set of environmental cues develops and acts as the fundamental framework on which subsequent information, such as paths, is added. The alternative proposal is that routes develop first, and landmarks are then placed in relation to them.

Gärling et al. (1981) suggested that paths need to be learnt before landmarks can be, as the routes act as a framework for the accurate recall of landmarks, i.e., routes need to be traversed to encounter landmarks and so will have to be remembered first. MacEachren (1992a; 1992b) claimed that evidence for the development of routes before landmarks comes from sketch-map data. For example, Appleyard (1970) and Devlin (1976) both found that short-term residents produced sketch maps that were path dominant, with residents based in the areas for longer periods of time producing more integrated maps, containing more landmarks. Other researchers (e.g., Allen and Kirasic, 1985; Allen, 1988) also found evidence to support this hypothesis. They discovered that routes are learnt through a segmentation process which over time and with frequent encounters are integrated into a complete cognitive structure.

However, there is also evidence that landmarks can form the initial framework for cognitive map knowledge. Siegel and White (1975) suggested that cognitive map knowledge is hierarchically organized into landmarks, routes and configurations, and that knowledge is acquired in that order. Closely related to Siegel and White's theory of development is Golledge's (1978) anchor-point theory. Golledge's (1978) theory emphasized the role of landmarks in the learning process. He suggested that different places have different salience to individuals and therefore become hierarchically structured. Primary nodes act as spatial primers which act as decision points. These cues are the anchors on which other information is 'hung', and they act as a spatial mnemonics, increasing the probability of recognizing, or knowing the position of, an associated target cue. Other landmarks have lower levels of use and recognizability (Golledge et al., 1987), each acting as minor anchors to the levels below. Secondary nodes identify places of decision-making, recreation and entertainment, such as major junctions, parks and cinemas. Tertiary nodes are usually places of minor decision-making (e.g., little-used junctions or little-known landmarks). Minor-order nodes are places that are specifically known, but which do not act as decision-making points, and these are often unique to the individual.

Couclelis et al. (1987) expanded upon Golledge's work, and suggested that nodes within the hierarchy may not necessarily represent landmarks but may include any feature that acts as a cognitive map cue or anchor. For example, a stretch of main road may act as a cue. Gärling et al. (1986), however, suggested that it might be better to look at reference points not as points but rather as areal extents, so that they become topical areas. These areas then act as the anchors for the rest of the cognitive map knowledge. Couclelis et al.'s (1987) anchor-point theory neatly combines Tversky's (1981) alignment and rotation heuristics with the spatial priming theory of McNamara et al. (1984; 1989; 1992). As such, key landmarks, linear features and areas 'individually and jointly "anchor" subregions of space and hierarchically link together environmental information' (Lee and Schmidt, 1988: 340).

At present, we do not as yet fully know the processes used by people with visual impairments or blindness to learn new environments or update existing knowledge. Hampson and Duffy (1984) and Butler (1995) suggest that blind individuals rely heavily on haptic and verbal instruction to learn new environments. Hampson and Duffy (1984) found that both sighted and blind individuals could learn the spatial relationships of 
shapes presented to them. As described above, Passini and Proulx (1988) found that blind individuals can learn routes through complex buildings, but we know little about the learning processes involved or the knowledge structures created. However, detailed work on the wayfinding and search activities of blind and vision-impaired persons has been conducted by Hill et al. (1993). These researchers stressed the significance of being able to establish orientation and a bounding frame of reference as contributors to successful wayfinding and exploration. They found significant similarities between the strategies used by blind or vision-impaired individuals and blindfolded and sighted groups. These strategies included: independent systematic exploration which varied according to the purposes under which such exploration took place; establishment of a significant and clearly defined anchor point as an origin; establishing the type of regularity found in the layout structure of the environment (e.g., regularities in the street system); establishing significant landmark cues which could be auditory, tactile, olfactory or locational; and as part of the preplanning process, choosing a path selection strategy such as minimizing obstacles, minimizing left turns or minimizing effort or time. In the consequent actions, wayfinders established object-to-object relations haptically, auditorially, proprioceptively (i.e., by sensing time and effort of movement), or used assistive devices such as canes or sensors. Hill et al. (1993) found that the best performers nearly always used an anchor point (object-to-object) strategy similar to that identified in the cognitive mapping and environmental learning processes by Golledge (1978) and Couclelis et al. (1987). Hill et al. (1993) found that visually impaired participants used a variety of wayfinding strategies and this individual variation has also been noted by other researchers (e.g., Loomis et al., 1993). This finding indicates the importance of considering individual differences in visually impaired people's spatial and wayfinding strategies and the relationship between individual strategies and degree of visual impairment. Such factors need to be considered in the context of different environments and the type of mobility aids which may be available (see Ungar et al., 1997).

\section{Future research}

The discussion has highlighted that despite the increasing research interest in the spatial activities of blind or vision-impaired persons, there is still considerable uncertainty about the spatial abilities and activity patterns of this group. The majority of research has taken place in small spaces, using short routes such as the corridors of buildings, or routes with few turns, and it is difficult to extrapolate performance in such spaces to performance in complex real-world environments. And, of course, there is the perennial geographic suspicion that there are scale effects in spatial competence. There is also some doubt about whether the findings from experimental situations in small-scale and rigidly controlled experimental settings bear any significant relationship to activities and behaviours in the uncontrolled obstacle-ridden real world. It is suspected by many that wayfinding in large-scale real spaces (e.g., residential areas or shopping malls) is different from wayfinding in limited areas - on the one hand there are more sources of information such as sound, smells and wind directions to aid route following and orientation in the geographic-scale spaces. On the other hand, there are distractions and complications resulting from the presence of obstacles, other people, and unexpected diversions and or barriers that might occur. Our ignorance about how such factors compensate each other, or interact, emphasizes the need to increase our knowledge of the cognitive mapping and 
spatial abilities of blind and vision-impaired people in environments where they are implemented on a daily basis.

Spencer et al. (1989) further noted that it is difficult to draw conclusions from much of the work in small spaces because there are contradictory findings. For example, several researchers in the UK have found differences between the cognitive maps of sighted versus blind persons (Dodds et al., 1982). Although this conclusion was supported by USA researchers, such as Rieser et al. (1992), other researchers in the USA (e.g., Klatzky et al., 1990; Loomis et al., 1993) found no significant differences between the performance of congenitally or adventitiously blinded individuals and blindfold sighted individuals on a variety of location, walking, turning and triangle completion tasks. However, most of these experiments were carried out in laboratory settings and it is yet to be established whether the same pattern of results would be found in studies carried out in complex geographic environments. We currently know very little about how people with visual impairment, or blindness understand a significantly large or complex geographic environment and how they can achieve an adequate spatial representation of a real-world setting. Questions arise concerning whether or not people with visual impairments have equivalent skills, abilities and knowledge structures (e.g., cognitive maps) as do sighted persons and whether such groups use the same strategies and require access to the same types of spatial information to solve problems of life experience as do those with sight. In other words, questions are raised as to whether performance on small-scale spatial tasks serves as any indication of large-scale spatial abilities and travel skills.

There are other questions relating to whether the social and political environments in which people without vision acquire navigation, orientation and other spatial skills produce different learning, coping and using strategies. Unanswered questions include: to what extent does the social and political milieu encourage or discourage the development of independence in travel and mobility of disabled persons such as those without vision? As noted, researchers in the UK and those in the USA have sometimes found differing results. There may be ethics involved in societal and political attitudes towards blind or vision-impaired persons in the USA and the UK. The UK has, for the most part, adopted a social welfare ethic and a set of programmes which offer a paternalistic approach to addressing the needs of disabled groups such as the blind or vision-impaired people. The USA has used more of a self-help approach in which mainstreaming, 'normalization' and independence have become the ethos of the society's approach to the needs of disabled groups. These attitudes are expressed in governmental policies towards those with disabilities. For example, the American Standards Act 1961, and the recent Americans with Disabilities Act 1990, are clear indications of the self-help approach. They are forms of civil rights and equal opportunity legislations which require environmental modification to remove those physical obstacles and barriers that impede the everyday actions and activities of disabled groups. But disabled people still have to live independently, undertake unassisted travel wherever possible and face the same problems of finding jobs suited to their skills and abilities as do able-bodied individuals. Given this emphasis on removing barriers to allow freer and independent use of existing skills, there is widespread belief of members of different disabled groups in the USA that they lead an independent life, with some obvious frustrations relating to employability and movement, but in general living a quality life rather than an impoverished one. There is little evidence that group members consider themselves to be 'victims', but rather they acknowledge that they are members of a distinct population with specific problems that can be overcome with dignity, self-reliance and pride. In the UK the equivalent to the 
American Standards Act 1961 was legislation providing for access for the disabled to buildings in 1967. This was the start of a significant movement towards creating obstaclefree environments for disabled people. It was, however, coupled with social welfare policies of compensation, special treatment, pragmatism and gradualism, which may not have produced the same enabling environment that was produced by the USA legislation. The question is whether different support systems produce different attitudes towards the development of geographic-scale spatial skills such as unassisted wayfinding strategies, heuristics for solving location, direction and orientation problems, and methods for integrating route-related experiences into integrated configurations or layouts.

As discussed in section II, we know little about how visually impaired or blind people process and use their spatial knowledge: to what extent does lack of vision impoverish cognitive map knowledge? How do people with visual impairments or blindness plan a journey? While travelling, what spatial decisions are taken? On what basis? From what set of alternatives? What unique or common problems are encountered on a route? What spatial abilities can technical aids compensate for? With what degree of success? How well is performance improved? Are there any changes in spatial behaviour after using assistive devices? How do people with visual impairments or blindness understand spatial language, including prepositions such as above, within, between, east/west, here, there, that way?

In terms of learning and understanding new environments, we are unsure as to how people with visual impairments or blindness learn a new environment and update existing knowledge with new information. For example, what exploration strategies are used by wayfinders who lack sight? What is the role of nonvisual spatial perception in the formation of cognitive map knowledge and active spatial behaviour by blind or visionimpaired people? How do the spatial abilities of the visually impaired or blind develop throughout childhood? Are there ways to improve spatial ability and knowledge in childhood that will affect adult cognition? We suggest that the questions raised in this section form a logical basis of a future research agenda. Note, we are suggesting that this research be complementary, rather than instead of, other studies focusing on the geographical experiences of disability.

\section{Conclusion}

Over the past 30 years geographers and psychologists have investigated how people learn, store and understand spatial relationships. However, this work has, to a large degree, failed to address how people with visual impairments experience and understand the world at the geographic scale. In this article we have discussed a number of theories relating to the contents and structure of spatial knowledge and how such knowledge is acquired. We have hypothesized how these theories might apply to people with visual impairments or blindness and highlighted a number of questions that need to be asked and answered if we are to make significant advances in understanding how people with visual impairments learn about the world. An increased understanding would be of particular benefit in considering the differences between visually impaired and sighted people's spatial knowledge and discovering any difficulties the former may have in pursuing real-world activities. Once visually impaired people's abilities are fully assessed in realistic conditions further consideration can be given to helping such people to acquire wayfinding and cognitive mapping skills more effectively, as well as contributing to the 
design of appropriate navigational aids which can compensate for some of the limitations in visually impaired people's spatial skills in geographic space. Further, this understanding can be used to inform educational curricula and to provide information which planners and architects can use to design places that are easier to learn and remember, and in turn this will give visually impaired people greater access to their environment. However, this understanding can only be brought about by new research which goes beyond previous studies which have usually focused on performance in small and limited environments. We hope that some of the issues and questions raised in this article will be a stimulus for that research.

\section{References}

Allen, G.L. 1981: A developmental perspective on the effects of subdividing macrospatial experience. Journal of Experimental Psychology: Human Learning and Memory 7, 120-32.

- 1982: The organization of route knowledge. In Cohen, R., editor, New directions for child development: children's conceptions of spatial relationships, San Francisco, CA: Jossey-Bass, 31-39.

1985: Strengthening weak links in the study of the development of macrospatial cognition. In Cohen, R., editor, The development of spatial cognition, Hillsdale, NJ: Lawrence Erlbaum Associates, 301-21.

1988: The acquisition of spatial knowledge under conditions of tempospatial discontinuity. Psychological Research 50, 183-90.

Allen, G. and Kirasic, K. 1985: Effects of the cognitive organization of route knowledge on judgments of macrospatial distance. Memory and Cognition 13, 218-27.

Anderson, J.R. and Bower, G.H. 1973: Human associative memory. New York: V.H. Winston \& Sons.

Andrews, S.K. 1983: Spatial cognition through tactual maps. In Wiedel, J., editor, Proceedings of the 1st international symposium on maps and graphics for the visually handicapped, Washington, DC: Association of American Geographers, 30-40.

Appleyard, D. 1970: Styles and methods of structuring a city. Environment and Behaviour 2, 100-17.

Balachandran, W. 1995: Satellite navigation system for blind pedestrians. Research at the University of Surrey. Paper presented at the conference on 'Orientation and navigation systems for blind persons', Hatfield, 1-2 February.

Banerjee, M. 1928: Blindfold description of distance. Indian Journal of Psychology 3, 95-99.

Bigelow, A. 1991: Spatial mapping of familiar locations in blind children. Journal of Visual Impairment and Blindness 85, 113-17.
Brabyn, J. 1995: Orientation and navigation systems for the blind: an overview of different approaches. Paper presented at the conference on 'Orientation and navigation systems for blind persons', Hatfield, 1-2 February.

Butler, D.L., Acquino, A.L., Hissong, A.A. and Scott, P.A. 1993: Wayfinding by newcomers in a complex building. Human Factors 35, 159-73.

Butler, R.E. 1995: Just a black hole - blind people's view of space. Unpublished manuscript, University of Reading.

Butler, R.E. and Bowlby, S. 1996: Disabled bodies in public space. Discussion Paper 43. Reading: University of Reading.

Byrne, R.W. and Salter, E. 1983: Distances and directions in cognitive maps of the blind. Canadian Journal of Psychology 37, 293-99.

Cadwallader, M.T. 1979: Problems in cognitive distance and their implications to cognitive mapping. Environment and Behaviour 11, 559-76.

Casey, S.M. 1978: Cognitive mapping by the blind. Journal of Vision Impairment and Blindness 72, 297-301.

Clark-Carter, D.D., Heyes, A.D. and Howarth, C.I. 1986: The efficiency and walking speed of visually impaired pedestrians. Ergonomics 29, 779-89.

Couclelis, H., Golledge, R.G., Gale, N. and Tobler, W. 1987: Exploring the anchor-point hypothesis of spatial cognition. Journal of Environmental Psychology 7, 99-122.

Cratty, B.J. 1966: Perception of inclined plane while walking without vision. Perceptual and Motor Skills 41, 547-56.

Devlin, A. 1976: The 'small town' cognitive map: adjusting to a new environment. In Moore, G.T. and Golledge, R.G., editors, Environmental knowing, Stroudsburg, PA: Dowden, Hutchinson \& Ross, 58-66.

Dodds, A.G., Howarth, C.I. and Carter, D.C. 1982: 
The mental maps of the blind. Journal of Visual Impairment and Blindness 76, 5-12.

Downs, R.M. and Stea, D. 1973: Cognitive maps and spatial behavior: process and products. In Downs, R.M. and Stea, D., editors, Image and environment, Chicago, IL: Aldine, 8-26.

Fishbein, H.D. 1976: An epigenetic approach to environmental learning theory. In Moore, G.T. and Golledge, R.G., editors, Environmental knowing, Stroudsburg, PA: Dowden, Hutchinson \& Ross, 131-36.

Fletcher, J.F. 1980: Spatial representations in blind children. 1. Development compared to sighted children. Journal of Visual Impairment and Blindness 74, 381-85.

_ 1981: Spatial representations in blind children. 2. Effects of task variations. Journal of Visual Impairment and Blindness 75, 1-3.

Foulke, E. 1983: Spatial ability and the limitations of perceptual systems. In Pick, H.L. and Acredolo, L., editors, Spatial orientation: theory, research and application, New York: Plenum Press, 125-41.

Fruchterman, J. 1995: Arkenstone's orientation tools: Atlas Speaks and Strider. Paper presented at the conference on 'Orientation and navigation systems for blind persons', Hatfield, 1-2 February.

Gale, N., Golledge, R.G., Halperin, W.C. and Couclelis, H. 1990: Exploring spatial familiarity. Professional Geographer 43, 299-313.

Gärling, T., Böök, A., Lindberg, E. and Nilsson, T. 1981: Memory for the spatial layout of the everyday physical environment: factors affecting rate of acquisition. Journal of Environmental Psychology 1, 263-77.

Gärling, T., Lindberg, E., Carreiras, M. and Book, A. 1986: Reference systems in cognitive maps. Journal of Environmental Psychology 6, 1-18.

Glicksohn, J. 1994: Rotation, orientation, and cognitive mapping. American Journal of Psychology $107,39-51$.

Golledge, R.G. 1978: Representing, interpreting and using cognized environments. Papers and Proceedings of the Regional Science Association 41, 169-204.

- 1991: Tactual strip maps as navigational aids. Journal of Visual Impairment and Blindness 85, 296-301.

- 1992: Place recognition and wayfinding: making sense of space. Geoforum 23, 199-214.

— 1993a: Geography and the disabled: a survey with special reference to vision impaired and blind populations. Transactions, Institute of British Geographers 18, 63-85.

— 1993b: Geographical perspectives on spatial cognition. In Gärling, T. and Golledge, R.G., editors, Behaviour and environment: psychological and geographical approaches, North Holland: Elsevier Press, 16-46.

Golledge, R.G., Costanzo, C.M. and Marston, J.R. 1996b: Public transit use by non-driving disabled persons: the case of the blind and visually impaired. California PATH Working Paper UCB-ITS-PWP96-1. Santa Barbara: University of California.

Golledge, R.G., Gale, N. and Richardson, G. 1987: Cognitive maps of cities: studies of selected populations. The National Geographical Journal of India 33, 1-16.

Golledge, R.G., Klatsky, R.L. and Loomis, J.M. 1996a: Cognitive mapping and wayfinding by adults without vision. In Portugali, J., editor, The construction of cognitive maps, Dordrecht: Kluwer, 215-45.

Golledge, R.G., Loomis, J.M., Klatzky, R.L., Flury, A. and Yang, X.L. 1991: Designing a personal guidance system to aid navigation without sight: progress on the GIS component. International Journal of Geographical Information Systems 5, 373-95.

Golledge, R.G., Smith, T.R., Pellegrino, J.W., Doherty, S. and Marshall, S.P. 1985: A conceptual model and empirical analysis of children's acquisition of spatial knowledge. Journal of Environmental Psychology 5, 125-52.

Haber, R.N., Haber, L.R., Levin, C.A. and Hollyfield, R. 1993: Properties of spatial representations: data from sighted and blind subjects. Perception and Psychophysics 54, 1-13.

Hampson, P.J. and Duffy, C. 1984: Verbal and spatial inference effects in congenitally blind and sighted subjects. Canadian Journal of Psychology $38,411-20$.

Hart, R. and Berzok, M.A. 1983: A problem oriented perspective on children's representation of the environment. In Potegal, M., editor, The neural and development bases of spatial orientation, New York: Academic Press, 147-72.

Hart, R.A. and Moore, G. 1973: The development of spatial cognition: a review. In Downs, R.M. and Stea, D., editors, Image and environment, Chicago, IL: Aldine, 246-88.

Herman, J.F., Chatman, S.P. and Roth, S.F. 1983: Cognitive mapping in blind people: acquisition of spatial relationships in a large scale environment. Journal of Visual Impairment and Blindness $77,161-66$.

Hill, E.W., Rieser, J.J., Hill, M., Halpin, J. and Halpin, R. 1993: How persons with visual impairments explore novel spaces: strategies of good and poor performers. Journal of Visual Impairment and Blindness 87, 295-301. 
Hollins, M. and Kelly, E.K. 1988: Spatial updating in blind and sighted people. Perception and Psychophysics 43, 380-88.

Hollyfield, R.L. and Foulke, E. 1983: The spatial cognition of blind pedestrians. Journal of Visual Impairment and Blindness 5, 204-209.

Imrie, R. 1996: Ablist geographies, disablist spaces: towards a reconstruction of Golledge's geography and the disabled. Transactions, Institute of British Geographers 21, 397-403.

Jacobson, R.D. 1992: Spatial cognition through tactile mapping. Swansea Geographer 29, 79-88.

Johnston, M. 1996: Models of disability. The Psychologist 9, 205-11.

Juurmaa, J. and Lehtinen-Railo, S. 1994: Visual experience and access to spatial knowledge. Journal of Visual Impairment and Blindness 88, 157-70.

Kaplan, S. 1973: Cognitive maps in perception and thought. In Downs, R.M. and Stea, D., editors, Image and environment, Chicago, IL: Aldine, 63-78.

Kitchin, R.M. 1994: Cognitive maps: what are they and why study them? Journal of Environmental Psychology 14, 1-19.

— 1996a: A geography of, for or with disabled people? Paper presented at the 4th young Welsh geographers conference, Gregynog, 15-16 March.

— 1996b: Increasing the integrity of cognitive mapping research: appraising conceptual schemata of environment-behaviour interaction. Progress in Human Geography 20, 56-84.

Klatzky, R.L. and Lederman, S.J. 1988: The representation of objects in memory: contrasting perspectives from vision and touch. In Gruneberg, M., Morris, P. and Sykes, R., editors, Practical aspects of memory: current research and issues. Vol. 2, New York: Wiley, 426-33.

Klatzky, R.L., Loomis, J.M., Golledge, R.G., Cicinelli, J., Doherty, S. and Pellegrino, J. 1990: Acquisition of route and survey knowledge in the absence of vision. Journal of Motor Behavior 22, 19-43.

Kosslyn, S.M. and Pomerantz, J.R. 1977: Imagery, propositions and the form of the internal representations. Cognitive Psychology 9, 52-76.

Kuipers, B. 1978: Modelling spatial knowledge. Cognitive Science 2, 129-53.

— 1982: The 'map in the head' metaphor. Environment and Behaviour 14, 202-20.

Lee, Y. and Schmidt, C.G. 1988: Evolution of urban spatial cognition: patterns of change in
Guangzhou, China. Environment and Planning A 20, 339-51.

Leonard, J.A. and Newman, R.C. 1967: Spatial orientation in the blind. Nature, September, 215.

Liben, L. 1981: Spatial representation and behavior: multiple perspectives: In Liben, L., Patterson, A.M. and Newcombe, N., editors, Spatial representation and behavior across the life span, New York: Academic Press, 3-36.

— 1991: Environmental cognition through direct and representational experiences: a life-span perspective. In Gärling, T. and Evans, G.W., editors, Environment, cognition and action - an integrated approach, New York: Plenum Press, 245-76.

Lloyd, R. 1989: Cognitive maps: encoding and decoding information. Annals of the Association of American Geographers 79, 101-24.

Loomis, J.M., Klatzky, R.L., Golledge, R.G., Cicinelli, J.G., Pellegrino, J.W. and Fry, P.A. 1993: Non-visual navigation by blind and sighted: assessment of path integration ability. Journal of Experimental Psychology: General 122, 73-91.

Lund, F.H. 1930: Physical asymmetries and disorientation. American Journal of Psychology 42, $51-62$.

MacEachren, A.M. 1992a: Application of environmental learning theory to spatial knowledge acquisition from maps. Annals of the Association of American Geographers 82, 245-74.

- 1992b: Learning spatial information from maps: can orientation-specificity be overcome? The Professional Geographer 44, 431-43.

McNamara, T.P. 1986: Mental representation in spatial relations. Cognitive Psychology 18, 87-121.

McNamara, T.P., Altarriba, J., Bendele, M., Johnson, S.C. and Clayton, K.N. 1989: Constraints on priming in spatial memory: naturally learned versus experimentally learned environments. Memory and Cognition 17, 444-53.

McNamara, T.P., Halpin, J.A. and Hardy, J.K. 1992: The representation and integration in memory of spatial and nonspatial information. Memory and Cognition 20, 519-32.

McNamara, T.P., Ratcliff, R. and McKoon, G. 1984: The mental representation of knowledge acquired from maps. Journal of Experimental Psychology: Learning, Memory and Cognition 10, 723-32.

Moar, I. and Bower, G. 1983: Inconsistency in spatial knowledge. Memory and Cognition 11, 107-13.

Paivio, A. 1979: Imagery and verbal processes. New York: Holt, Rinehart \& Winston.

Parkes, D. 1988: NOMAD - an audio-tactile tool for the acquisition, use and management of 
spatially distributed information by partially sighted and blind people. In Dodds, A. and Tatham, A., editors, Proceedings of the second international conference on maps and graphics for the visually disabled, London: King's College, 24-29.

Passini, R., Dupré, A. and Langlois, C. 1986: Spatial mobility of the visually handicapped active person: a descriptive study. Journal of Visual Impairment and Blindness 80, 904-907.

Passini, R. and Proulx, G. 1988: Wayfinding without vision: an experiment with congenitally blind people. Environment and Behaviour 20, 227-52.

Passini, R., Proulx, G. and Rainville, C. 1990: The spatio-cognitive abilities of the visually impaired population. Environment and Behaviour 22, 91-118.

Petrie, H. 1995: User requirements for a GPS-based travel aid for blind people. Paper presented the conference on 'Orientation and navigation systems for blind persons', Hatfield, 1-2 February.

Piaget, J. and Inhelder, B. 1967: The child's conception of space. New York: Norton.

Pick, H.L. 1980: Perception, locomotion and orientation. In Welsch, R.L. and Blasch, B.B., editors, Foundations of orientation and mobility, New York: American Foundation for the Blind, 73-88.

Pufall, P.B. and Shaw, R. 1973: Analysis of the development of children's spatial reference systems. Cognitive Psychology 5, 151-75.

Rieser, J.J., Guth, D.A. and Hill, E.W. 1986: Sensitivity to perspective structure while walking without vision. Perception 15, 173-88.

Rieser, J.J., Hill, E.W., Taylor, C.R., Bradfield, A. and Rosen, S. 1992: Visual experience, visual field size, and the development of nonvisual sensitivity to the spatial structure of outdoor neighborhoods explored by walking. Journal of Experimental Psychology: General 121, 210-21.

Rieser, J.J., Lockman, J.L. and Pick, H.L. 1980: The role of visual experience in knowledge of a spatial layout. Perception and Psychophysics 28, 185-90.

Siegel, A.W. and White, S. 1975: The development of spatial representation of large scale environments. In Reese, H., editor, Advances in child development and behavior. Vol. 10, New York: Academic Press, 9-55.

Spencer, C., Blades, M. and Morsley, K. 1989: The child in the physical environment. Chichester: Wiley.
Stevens, A. and Coupe, P. 1978: Distortions in judged spatial relations. Cognitive Psychology 10, 422-37.

Tellevik, J.M. 1992: Influence of spatial exploration patterns on cognitive mapping by blindfolded sighted persons. Journal of Visual Impairment and Blindness 86, 221-24.

Thorndyke, P.W. 1983: Spatial cognition and reasoning. In Harvey, J., editor, Cognition, social behavior and the environment, Hillsdale, NJ: Lawrence Erlbaum, 137-49.

Tversky, B. 1981: Distortions in memory for maps. Cognitive Psychology 13, 407-33.

1992: Distortions in cognitive maps. Geoforum 23, 131-38.

Ungar, S., Bayal, A.E., Blades, M., Ochaita, E. and Spencer, C. 1997: Blind and visually impaired people using tactile maps. Cartographic Perspectives, in press.

Ungar, S., Blades, M. and Spencer, C. 1996: The construction of cognitive maps by children with visual impairments. In Portugali, J., editor, The construction of cognitive maps, Dordrecht: Kluwer.

Ungar, S., Blades, M., Spencer, C. and Morsley, K. 1994: Can young visually impaired children use maps to estimate directions in the environment? Journal of Visual Impairment and Blindness 88, 221-33.

von Senden, S.M. 1932: Space and sight: the perception of space and shape by the congenitally blind before and after operation. Glencoe, IL: Free Press.

Vujakovic, P. and Matthews, M.H. 1994: Contorted, folded, torn: environmental values, cartographic representation and the politics of disability. Disability and Society 9, 359-75.

Warren, D.H., Rossano, M.J. and Wear, T.D. 1990: Perception of map-environment correspondence: the roles of features and alignment. Ecological Psychology 2, 131-50.

Werner, H. 1957: The concept of development from a comparative and organismic point of view. In Harris, D.B., editor, The concept of development? Minneapolis, MN: University of Minnesota Press.

Worchel, P. 1951: Space perception and orientation in the blind. Psychological Monographs: General and Applied 65, 1-27. 